\title{
Bataryalı PV Sistemlerde Maksimum Güç Noktası Takip Yöntemlerinin Karşılaştırılması
}

\author{
Nihan Altintaş ${ }^{1 *}$, Ahmet Yilmaz $^{2}$, Alparslan Demirci $^{3}$, Said Mirza Tercan ${ }^{4}$ \\ 1*Yıldız Teknik Üniversitesi, Elektrik-Elektronik Fakültesi, İstanbul, Türkiye (ORCID: 0000-0002-6567-7675), naltin@ yildiz.edu.tr \\ ${ }^{2}$ Ylldız Teknik Üniversitesi, Elektrik-Elektronik Fakültesi, İstanbul, Türkiye (ORCID: 0000-0002-9359-6434), ahmetylmz23yilmaz@gmail.com \\ ${ }^{3}$ Y 1 ldız Teknik Üniversitesi, Elektrik-Elektronik Fakültesi, İstanbul, Türkiye (ORCID: 0000-0002-1038-7224), ademirci@ yildiz.edu.tr \\ ${ }^{4}$ Yıldız Teknik Üniversitesi, Elektrik-Elektronik Fakültesi, İstanbul, Türkiye (ORCID: 0000-0003-1663-713X), stercan@ yildiz.edu.tr
}

(İlk Geliş Tarihi 11 Mart 2020 ve Kabul Tarihi 25 Ocak 2021)

(DOI: $10.31590 /$ ejosat.702393)

ATIF/REFERENCE: Altıntaş, N., Yılmaz, A., Demirci, A. ve Tercan, S.M. (2021). Bataryalı PV Sistemlerde Maksimum Güç Noktası Takip Yöntemlerinin Karşılaştırılması. Avrupa Bilim ve Teknoloji Dergisi, (21), 369-377.

\section{$\ddot{O ̈ z}$}

Son yıllarda alternatif enerji sistemlerine olan ilginin artmasına paralel olarak güneş enerjisi sistemlerinin kullanımı da artmaktadır. Genellikle evlerin çatılarına kurulan küçük güçlü bu sistemler PV (Photovoltaic, Fotovoltaik) panellerden oluşur. PV sistemlerde üretilen enerji, güneş ışınlarının açısı, hava sıcaklığı, rüzgâr gibi birçok parametreye bağlıdır. Bu nedenle PV sistemlerin akım-gerilim karakteristikleri doğrusal olmayıp verimleri belirtilen bu parametrelere bağlı olarak değişir. PV panellerinden maksimum verim elde edebilmek için maksimum güç noktası takip (MGNT) yöntemlerinin kullanılması zorunlu hale gelmiştir. Bu çalışmada literatürde en çok kullanılan gradient tabanlı yöntemler arasından değiştir\&gözle (DG) ve artımlı iletkenlik (Aİ) yöntemleri, pasif yöntemler arasından ise sabit gerilim (SG) ve açık devre gerilimi (ADG) yöntemleri seçilmiş ve detaylı olarak incelemiştir. Modellemeler ve simülasyonlar MATLAB® Simulink ortamında gerçekleştirilmiştir. MGNT yöntemlerinin performanslarını karşılaştırmak için Yıldız Teknik Üniversitesi Davutpaşa Yerleşkesinde yapılan ölçümler ile elde edilmiş değişken ışıma değerleri kullanılmıştır.

Anahtar Kelimeler: Maksimum güç noktası takibi, değiştir\&gözle, artımlı iletkenlik, sabit gerilim, açık devre gerilimi.

\section{Comparison of Maximum Power Point Tracking Methods in Battery PV Systems}

\begin{abstract}
In recent years, using of solar energy systems has been increasing in parallel with the growing interest in alternative energy systems. These systems, usually installed on the roofs of the houses, consist of solar Photovoltaic (PV) panels. The energy produced in PV systems varies depending on many parameters such as angle of sun rays, temperature and wind. Therefore, the current-voltage characteristic of PV systems is not linear and their efficiency varies depending on each parameters. It is necessary to use maximum power point tracking (MPPT) methods to obtain maximum efficiency. In this study, the most commonly used in the literature as gradient based MPPT methods which are perturb\&observe (PO) and incremental conductance (IC), as passive methods which are constant voltage $(\mathrm{CV})$ and open circuit voltage $(\mathrm{OCV})$ are selected and detaily examined. Modelling and simulations were realized in MATLAB ${ }^{\circledR}$ Simulink environment. Variable irradiance values obtained in Yıldız Teknik University Davutpaşa Campus were used to compare performances of MPPT methods.
\end{abstract}

Keywords: Maximum power point tracking, perturb\&observe, incremental conductance, constant voltage, open circuit voltage.

*Sorumlu Yazar: naltin@yildiz.edu.tr 


\section{Giriş}

Son yıllarda yenilenebilir enerji sistemleri, içinde yaşadığımız evrenin yaşanılabilir kalması için ortaya çıkmış çevreci bir alternatiftir. Kurulum maliyetlerinin uygun ve entegrasyonunun kolay olmasıyla güneş enerjisine ilgi hızla artmaktadır. Fosil yakıtların azalması ve çevre sorunlarının giderek artması sebebiyle yenilenebilir enerji sistemlerine yönelişin giderek artacağı öngörülmektedir. Bununla birlikte günümüzde güneş enerjisi ile üretilen enerjinin hala dünyanın enerji üretiminde küçük bir paya sahip olduğu görülmektedir.

Güneş enerjisi dönüşüm sistemleri şebekeye entegreli veya şebekeden bağımsız olarak gerçekleştirilebilmektedir [1]. Her iki sistemde de panellerin toplam gücü arttıkça panellerin maksimum güç noktasında çalışmasının önemi artar. Çünkü PV sistemler doğrusal olmayan elektriksel özelliklere sahiptir. Sıcaklık, rüzgâr, 1şıma gibi atmosferik hava olaylarına bağlı olarak panellerin akım ve gerilimleri değişiklik gösterir. MGNT kontrol algoritmaları, PV panellerin akım ve gerilimlerini takip ederek panellerin çıkış gücünün maksimum olmasını sağlamak üzere dönüştürücünün darbe genişlik modülasyonu (PWM) oranını düzenler [2].

Güneş enerjisini daha verimli kullanabilmek için birçok MGNT algoritması ve yöntemi geliştirilmiştir [3]-[10]. MGNT yöntemleri kontrol stratejisine ve kullanılan sensör sayısına göre iki başlık altında sınıflandırılır. Kontrol stratejisine göre; gradient tabanlı, pasif (dolaylı) ve tahminsel MGNT yöntemleri mevcuttur. Kullanılan sensör sayısına göre; tek sensörlü ve iki sensörlü MGNT yöntemleri bulunmaktadır [11]. Tablo 1'de literatürdeki MGNT yöntemleri ile ilgili çalışmaların detaylı bir özeti verilmiştir. Bu tabloda MGNT yöntemleri, sıcaklık ve ışıma değerleri, deneysel veri kullanılıp kullanılmadığı, karmaşıklık, kullanılan sensör (akım, gerilim) sayısı, maliyet, verim ile fiyat/performans gibi özellikler açısından incelenmiştir.

Sonuç olarak literatürdeki çalışmalar incelendiğinde, deneysel verilerin kullanıldığı, üretim karmaşıklığı az olan, minimum sayıda sensör kullanılan, maliyetin düşük olduğu ve yüksek sistem verimine sahip MNGT yöntemleri öne çıkmaktadır. Bu çalışmada İstanbul ili Esenler ilçesine ait gerçek 1şıma verileri kullanılarak, öne çıkan aktif ve pasif MGNT yöntemlerinden değiştir\&gözle (DG), artımlı iletkenlik (Aİ), sabit gerilim (SG) ve açık devre gerilimi (ADG) yöntemlerinin performansları karşılaştırılmıştır. PV panel çıkışına bağlanan düşürücü DC-DC dönüştürücü devresi ile çıkış gerilimi sabit tutulmuştur. Dönüştürücü çıkışında bulunan batarya sabit gerilim altında şarj edilmiştir.

Bu çalşımada özetle, Bölüm 2'de PV sistemlerin çalışma prensibi ile temel özellikleri ve MGNT'nin önemi açıklanmıştır. Bölüm 3'te MGNT yöntemlerini aynı şartlar altında karşılaştırmak amacı ile 12 V'luk bataryayı şarj edebilen DC-DC düşürücü dönüştürücünün tasarımı yapılmıştır. Bölüm 4'te, PV sistemlerde kullanılan dört adet MGNT Yöntemi incelenmiştir. Bölüm 5'te, MGNT Yöntemleri sabit $25^{\circ} \mathrm{C}$ sıcaklıktaki değişken 1şıma değeri için MATLAB ${ }^{\circledR}$ Simulink programı kullanılarak modellenmiş ve yöntemler aynı şartlar altında karşılaştırılmıştır. Sonuç olarak, bu çalışmada PV sistemlerde en çok kullanılan gradient tabanlı ve pasif MGNT yöntemlerinin sabit sıcaklık ve değişken 1şıma değeri için simülasyonları yapılmış ve teorik olarak hesaplanan maksimum güce yaklaşma performansları karşılaştırılmıştır.

Tablo 1. MGNT yöntemleri

\begin{tabular}{|c|c|c|c|c|c|c|c|c|}
\hline REF. & $\begin{array}{l}\text { MGNT } \\
\text { yöntemi }\end{array}$ & Sicaklık & Işıma & $\begin{array}{c}\text { Deneysel } \\
\text { veri } \\
\text { kullanımı }\end{array}$ & $\begin{array}{c}\text { Üretim } \\
\text { karmaşıklığı }\end{array}$ & $\begin{array}{c}\text { Kullanılan } \\
\text { Sensör }\end{array}$ & Maliyet & $\begin{array}{l}\text { Verim } \\
(\%)\end{array}$ \\
\hline [3] & $\begin{array}{l}\text { Yeni } \\
\text { yöntem }\end{array}$ & $\begin{array}{c}\text { Dikkate } \\
\text { alınmamış }\end{array}$ & Değişken & Evet & Orta & V & Ucuz & 92.00 \\
\hline [4] & DG & Değişken & Değişken & Hayır & Orta & $\mathrm{V}, \mathrm{I}$ & - & - \\
\hline [5] & $\begin{array}{l}\text { DG } \\
\text { Fuzzy }\end{array}$ & Sabit & Değişken & Hayır & $\begin{array}{l}\text { Orta } \\
\text { Çok }\end{array}$ & $\begin{array}{l}\text { V, I } \\
\text { V, I }\end{array}$ & - & - \\
\hline [6] & $\begin{array}{l}\text { DG } \\
\text { AI } \\
\text { Fuzzy }\end{array}$ & $\begin{array}{l}\text { Dikkate } \\
\text { alınmamış }\end{array}$ & Değişken & Hayır & $\begin{array}{l}\text { Orta } \\
\text { Orta } \\
\text { Çok }\end{array}$ & $\begin{array}{l}\text { V, I } \\
\text { V, I } \\
\text { V, I }\end{array}$ & - & - \\
\hline [7] & $\begin{array}{l}\text { SG } \\
\text { ADG } \\
\text { DG } \\
\text { Mod. DG } \\
\text { AI } \\
\text { Fuzzy } \\
\text { YSA }\end{array}$ & $\begin{array}{c}\text { Dikkate } \\
\text { alınmamış }\end{array}$ & $\begin{array}{l}\text { Dikkate } \\
\text { alınmamış }\end{array}$ & Hayır & $\begin{array}{c}\mathrm{Az} \\
\mathrm{Az} \\
\text { Orta } \\
\text { Çok } \\
\text { Orta } \\
\text { Çok } \\
\text { Çok }\end{array}$ & $\begin{array}{c}\text { V } \\
\text { I } \\
\text { V, I } \\
\text { V, I } \\
\text { V, I } \\
\text { V, I } \\
\text { V ya da I }\end{array}$ & $\begin{array}{l}\text { Ucuz } \\
\text { Ucuz } \\
\text { Pahalı } \\
\text { Pahal1 } \\
\text { Pahal1 } \\
\text { Pahal1 } \\
\text { Pahal1 }\end{array}$ & - \\
\hline [9] & $\begin{array}{l}\mathrm{SG} \\
\mathrm{DG} \\
\mathrm{AI}\end{array}$ & Değişken & Değişken & Evet & $\begin{array}{c}\mathrm{Az} \\
\text { Orta } \\
\text { Orta }\end{array}$ & $\begin{array}{c}\mathrm{V} \\
\mathrm{V}, \mathrm{I} \\
\mathrm{V}, \mathrm{I}\end{array}$ & $\begin{array}{c}\text { Ucuz } \\
\text { Pahalı } \\
\text { Pahalı }\end{array}$ & $\begin{array}{l}91.88 \\
91.42 \\
93.83\end{array}$ \\
\hline [12] & AI & Değişken & Değişken & Evet & Orta & $\mathrm{V}, \mathrm{I}$ & Pahalı & 96.60 \\
\hline
\end{tabular}




\section{Fotovoltaik Sistemler}

Güneşten gelen fotonları elektrik enerjisine dönüştürmek için PV paneller tasarlanmıştır. PV panellerin çalışma prensibi p$\mathrm{n}$ ekleminden oluşan diyotların çalışma prensibine benzer. Güneş 1şınlarından gelen fotonlar sayesinde $\mathrm{N}$ tipi bölgede bulunan fazla elektronlar, elektron eksikliği bulunan P tipi bölgeye doğru hareket ederler ve bunun sonucunda bir elektrik akımı oluşur. Güneş enerjisi bu sayede doğrudan elektrik enerjisine dönüştürülür. PV paneller birçok seri veya paralel hücrenin yan yana gelmesiyle oluşturulur.

Şekil 1'de PV hücrenin elektriksel modeli verilmiştir. PV hücresi, ideal bir akım kaynağı ile paralel diyottan oluşur ve PV hücrenin maruz kaldığı güneş ışınımına orantılı bir akım sağlar. Elektriksel modelde V çıkış gerilimi, Iph foton akımı sabit bir kaynak olarak gösterilmektedir. Devre seri bağlı bir direnç (Rs), paralel bağlı bir direnç (Rp) ve bir diyottan (D) oluşmaktadır. PV panelin elektriksel eşdeğer modeli I çıkış akımına bağlıdır.

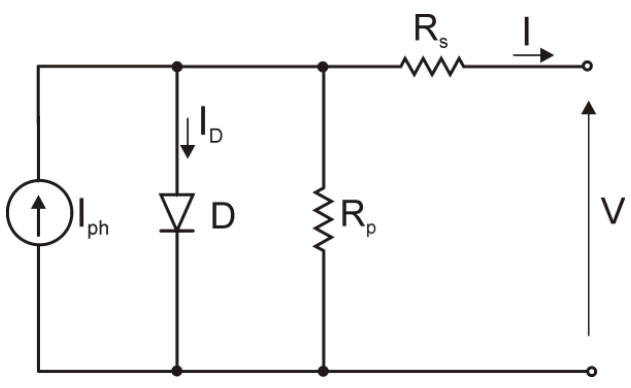

Şekil 1. PV hücrenin elektriksel modeli [8]

Bir PV hücresini tanımlarken kısa devre akımı $\mathrm{I}_{\mathrm{kd}}$ ve açık devre gerilimi $\mathrm{V}_{\text {ad }}$ parametreleri hayati önem taşır. Kısa devre durumunda diyot gerilimi $\mathrm{V}_{\mathrm{d}}=0$ olur. $\mathrm{Bu}$ durum, ideal akım kaynağındaki tüm akımın kısa devre terminallerinden geçtiği anlamına gelir. I çıkış akımı;

$$
I=I_{k d}-I_{D}
$$

$I_{D}$ diyot akımı aşağıdaki gibi bulunur.

$$
I_{D}=I_{s} \times\left(e^{\frac{q \times V \times d}{k \times T}}-1\right)
$$

Burada; $\mathrm{I}_{\mathrm{s}}$ ters doyum akımını, $\mathrm{V}_{\mathrm{d}}$ diyot gerilimini ve $\mathrm{T}$ ise jonksiyon sıcaklığını göstermektedir. q elektron şarj sabiti ve k Boltzmann sabiti katsayılar1 $1.6 \times 10^{-19} \mathrm{C}$ ve $1.38 \times 10^{-23} \mathrm{~J} / \mathrm{K}$ olarak alınmıştır. Sabit bir $T$ sıcaklığındaki $I_{s}$ ters doyum akımı aşağıdaki formülden bulunur.

$$
\mathrm{I}_{s}=\frac{\mathrm{I}_{\mathrm{kd}}}{e^{\frac{q \times V \times d}{k \times T}}-1}
$$

$$
I=I_{k d}-I_{s} \times\left(e^{\frac{q \times\left(V+I \times R_{s}\right)}{k \times T}}-1\right)-\frac{V+I \times R_{s}}{R_{p}}
$$

Şekil 2'de PV hücresinin gerilim akım karakteristiği görülmektedir. Maksimum Güç Noktasında (MGN), panel akımı $\left(\mathrm{I}_{\mathrm{MGN}}\right)$ ve panel gerilimi $\left(\mathrm{V}_{\mathrm{MGN}}\right)$ maksimumdur. $\mathrm{PV}$ hücresinin maksimum güç çıkışı $\mathrm{P}_{\max }=\mathrm{I}_{\mathrm{MGN}}$. $\mathrm{V}_{\mathrm{MGN}}$ şeklindedir. Bu çalışmada kullanılacak PV panelin elektriksel özellikleri Tablo 2'de verilmiştir.

Şekil 3'de, seçilen panelin $25^{\circ} \mathrm{C}$ 'deki $1000 \mathrm{~W} / \mathrm{m}^{2}, 500 \mathrm{~W} / \mathrm{m}^{2}$ ve $100 \mathrm{~W} / \mathrm{m}^{2}$ için 1 şıma değerlerine ait gerilim güç karakteristiği verilmiştir. Şekil 4'te sabit $1000 \mathrm{~W} / \mathrm{m}^{2}$ için değişken sıcaklıklarda panelin vermesi beklenen gerilim-güç değerleri verilmiştir. Şekilden de görüldüğü gibi sıcaklık değişiminin güce etkisi ihmal edilebilecek kadar azdır.

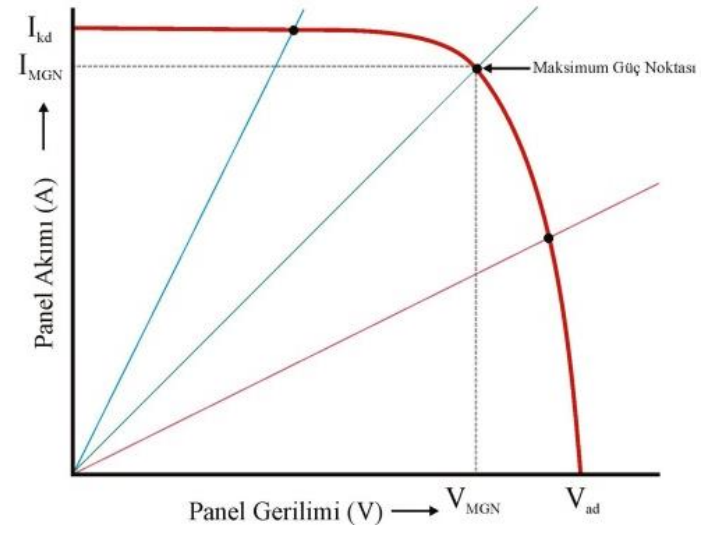

Şekil 2. PV hücrenin gerilim akım karakteristiği

Tablo 2. Aavid Solar Panel (ASMS-165P)

\begin{tabular}{l|l}
\hline Maksimum Güç & $\mathrm{P}_{\max }=164.85 \mathrm{~W}$ \\
\hline Açık Devre Gerilimi & $\mathrm{V}_{\mathrm{ad}}=43.5 \mathrm{~V}$ \\
\hline Kısa Devre Akımı & $\mathrm{I}_{\mathrm{kd}}=5.25 \mathrm{~A}$ \\
\hline MGN Gerilimi & $\mathrm{V}_{\mathrm{MGN}}=35 \mathrm{~V}$ \\
\hline MGN Akımı & $\mathrm{I}_{\mathrm{MGN}}=4.71 \mathrm{~A}$ \\
\hline
\end{tabular}

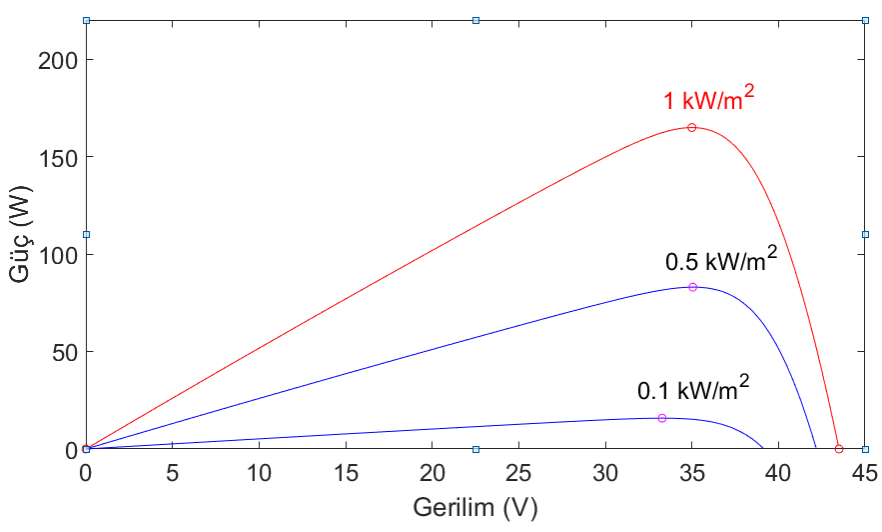

Şekil 3. Farklı 1şıma değerleri için gerilim-güç grafiği

$\mathrm{I}_{\mathrm{D}}$ diyot akımı, (1) numaralı denklemde yerine konursa PV hücresinin akım gerilim arasındaki bağlantıyı verir. 


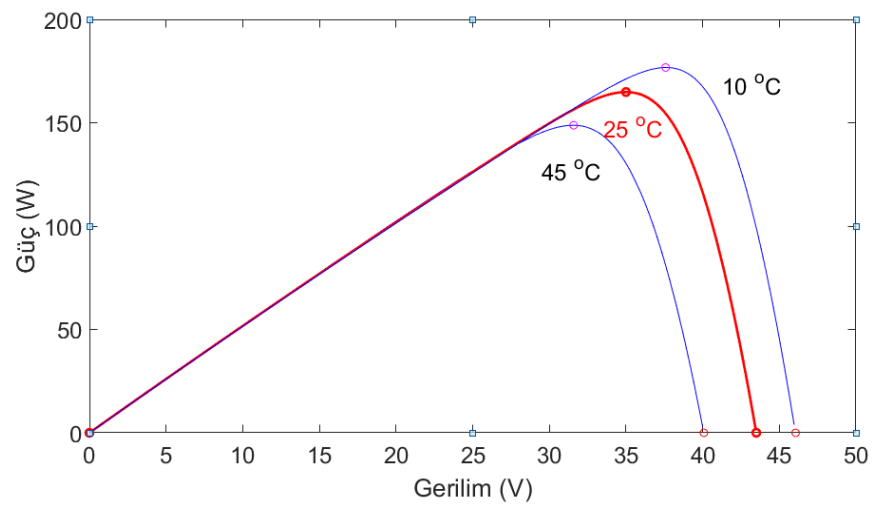

Şekil 4. Farklı sıcaklık değerleri için gerilim-güç grafiği

\section{DC-DC Dönüștürücünün Tasarımı}

$\mathrm{Bu}$ çalışmada kullanılacak PV panelin verebileceği maksimum güç çıkışı yaklaşık olarak $164.85 \mathrm{~W}$ ve maksimum gerilim değeri de $35 \mathrm{~V}$ 'dur. Batarya şarjı için PV gerilimi $12 \mathrm{~V}$ seviyesine DC-DC dönüştürücü ile düşürülecektir. Dönüştürücünün çıkış akımındaki dalgalanma en fazla $1 \mathrm{~A}$ ve çıkış gerilimindeki dalgalanma ise en fazla $0.4 \mathrm{~V}$ olacak şekilde devre tasarlanacaktır. Ayrıca eleman boyutlarının küçük olması için dönüştürücünün anahtarlama frekans $20 \mathrm{kHz}$ seçilmiştir.

Düşürücü DC-DC dönüştürücü devre şeması Şekil 5'de verilmiştir. Düşürücü türdeki DC-DC dönüştürücüler giriş geriliminin altında bir çıkış gerilimi elde etmek için kullanılır. $\mathrm{Bu}$ devrede $\mathrm{S}$ anahtarlama elemanı olarak MOSFET kullanılmıştır. Çıkış gerilimini filtrelemek için yüke paralel $\mathrm{C}$ çıkış kondansatörü, çıkış akımını filtrelemek için de yüke seri bağlı L çıkış endüktansı kullanılmıştır. Burada anahtarlama elemanı iletimde iken $\mathrm{Vg}$ giriş gerilimi hem L endüktansını hem de $\mathrm{R}$ yükünü besler. $\mathrm{S}$ anahtarlama elemanı kesimde iken $\mathrm{L}$ endüktansında depo edilen enerji $\mathrm{R}$ yükünü beslemeye devam eder [13].

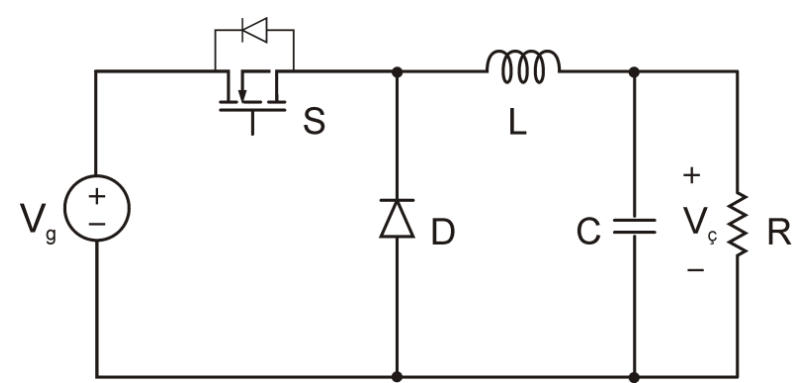

Şekil 5. Düşürücü DC-DC dönüştürücü genel devre şeması [13]

Simülasyonları gerçekleştirmek üzere devrede kullanılması gereken kondansatör ve endüktans değerleri aşağıdaki gibi hesaplanır. Bu hesaplamalarda devredeki elemanlar ideal kabul edilerek, devre kayıpları ihmal edilmiştir.

Düşürücü DC-DC dönüştürücülerin giriş ve çıkış gerilimleri arasında bağıl iletim süresine $(\lambda)$ bağlı ifade aşağıda verilmiştir.

$$
\mathrm{V}_{c}=\lambda \times \mathrm{V}_{\mathrm{g}}
$$

Giriş ve çık1ş gerilimleri yerine konulduğunda bağıl iletim süresi 0.42 olarak hesaplanır. Çıkış kondansatörü (C); çıkış akımındaki dalgalanma miktarı $\left(\Delta \mathrm{I}_{\varsigma}\right)$, anahtarlama frekansı (f) ve çıkış gerilimindeki dalgalanma miktarı $\left(\Delta \mathrm{V}_{\mathrm{C}}\right)$ 'ye bağlı olarak aşağıdaki gibi yazılabilir.

$$
\mathrm{C}=\frac{\Delta \mathrm{I}_{\mathrm{c}}}{8 \times \mathrm{f} \times \Delta \mathrm{V}_{\mathrm{c}}}
$$

(6) nolu ifadede değerler yerine konduğu takdirde kondansatör değeri $15.62 \mu \mathrm{F}$ olarak bulunur.

Endüktans değeri (L); bağıl iletim süresi $(\lambda)$, giriş gerilimi $\left(\mathrm{V}_{\mathrm{g}}\right)$, anahtarlama frekansı (f) ve çıkış akımındaki dalgalanma miktarına $\left(\Delta \mathrm{I}_{C}\right)$ 'ye bağlı olarak aşağıdaki şekilde yazılabilir.

$$
L=\lambda \times(1-\lambda) \times \frac{V_{g}}{f \times \Delta I_{c ̧}}
$$

(7) nolu ifadede değerler yerine konduğu takdirde endüktans değeri $426.3 \mu \mathrm{H}$ olarak bulunur. Simülasyon devresinde çıkış gerilim ve akımındaki dalgalanmaların daha az olması için $\mathrm{L}$ ve C değerleri sırasıyla $0.5 \mathrm{mH}$ ve $100 \mu \mathrm{F}$ olarak seçilmiştir.

Şekil 6'da, hesaplanan devre parametrelerine göre MATLAB simulink ortamında gerçekleştirilen devre şeması verilmiştir. $\mathrm{Bu}$ çalışmada incelenen MGNT yöntemleri aynı şartlar altında Şekil 6'daki devre kullanılarak gerçekleştirilmiştir.

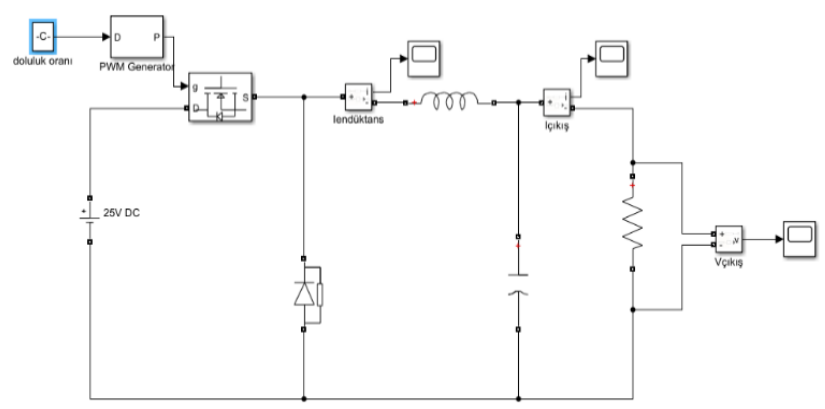

Şekil 6. MATLAB simulinkte gerçekleştirilen devre

\section{Fotovoltaik Sistemlerde Maksimum Güç Noktasi Takip Yöntemleri}

\subsection{Değiştir\&Gözle Yöntemi}

DG yönteminde PV gerilimi ve akımı, akım ve gerilim sensörleri kullanılarak ölçülür ve elde edilen güç $\mathrm{P}_{\mathrm{k}-1}$ hesaplanır. Ardından gerilimde $\Delta \mathrm{V}$ kadarlık bir fark tanımlanır ve bu yeni durum için $\mathrm{P}_{\mathrm{k}}$ hesaplanır. Eğer $\mathrm{P}_{\mathrm{k}-1}, \mathrm{P}_{\mathrm{k}}$ 'den büyük ise maksimum noktaya yaklaşılmaktadır. Aynı yönde gerilim arttırılmaya devam edilir. $\mathrm{P}_{\mathrm{k}}, \mathrm{P}_{\mathrm{k}-1}$ 'den büyük ise elde edilen güç maksimum güç noktasından uzaklaşılmaktadır ve gerilimin düşürülmesi gerekir [14]. Şekil 7'deki DG algoritmasının akış diyagramının MATLAB simulinkte kurulan modeli Şekil 8'de verilmiştir. Bu modelde ilk olarak $\mathrm{V}_{\mathrm{pv}}$ (panel gerilimi) ve $\mathrm{I}_{\mathrm{pv}}$ (panel akımı) ölçülmektedir. Daha sonra $\mathrm{P}=\mathrm{I}$.V formülünden güncel güç $\left(\mathrm{P}_{\mathrm{k}}\right)$ hesaplanmakta ve akabinde $\mathrm{P}_{\mathrm{k}}$ ile $\mathrm{P}_{\mathrm{k}-1}$ fark1 incelenmektedir. Eğer $\mathrm{P}_{\mathrm{k}}, \mathrm{P}_{\mathrm{k}-1}$ değerine eşit ise kontrol döngüsü başa döner. Eğer $\mathrm{P}_{\mathrm{k}}, \mathrm{P}_{\mathrm{k}-1}$ değerinden büyük veya küçük ise bu defa panelin gerilim değişimine bakılır. $P_{k}, P_{k-1}$ 'den büyük ise ve $V_{k}, V_{k-1}$ değerinden büyük ise doluluk oranı arttırılır. Eğer $V_{k}, V_{k-1}$ değerinden küçük ise doluluk oranı azaltılır. Diğer taraftan $\mathrm{P}_{\mathrm{k}}, \mathrm{P}_{\mathrm{k}-1}$ 'den küçük ise 372 
ve $V_{k}, V_{k-1}$ değerinden büyük ise doluluk oranı azaltılır. Eğer $V_{k}$, $\mathrm{V}_{\mathrm{k}-1}$ değerinden küçük ise doluluk oranı arttırılır.

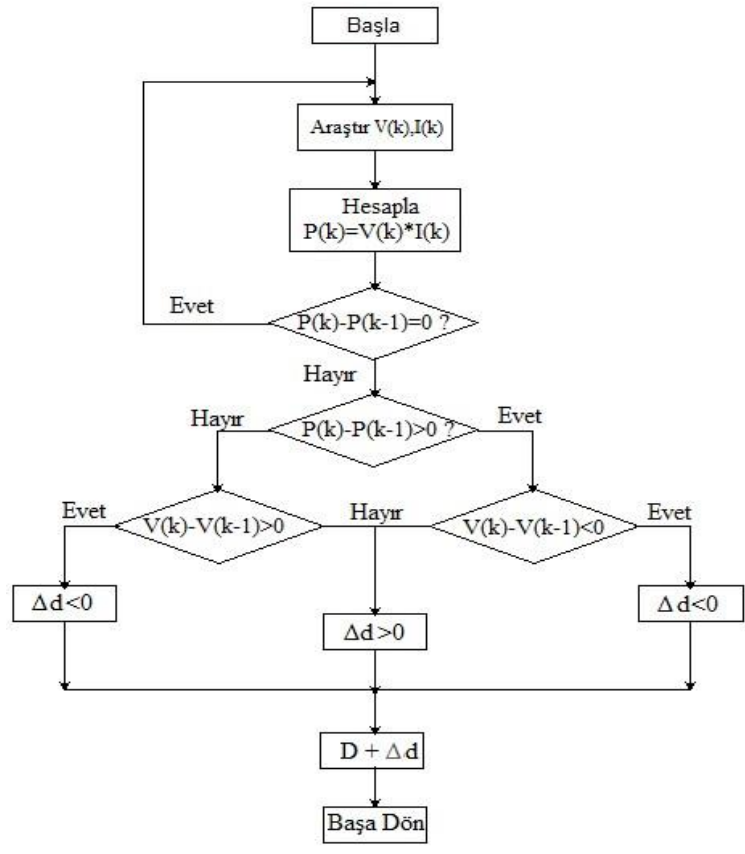

Şekil 7. DG yönteminin algoritması [15]

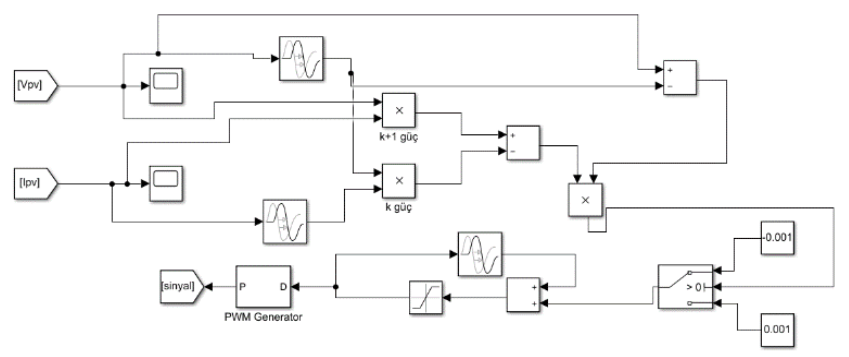

Şekil 8. DG algoritmasının MATLAB simulink modeli

\subsection{Artımlı İletkenlik Yöntemi}

Aİ yöntemi değişken atmosfer koşullarında bile hızlı adaptasyon ve doğruluk gösterdiğinden dolayı yaygın olarak kullanılan bir yöntemdir. $\mathrm{Bu}$ yöntemde temel olarak direk güçteki değişimler kullanılır. PV panelin iletkenliği $\left(\mathrm{C}=\frac{\mathrm{I}}{\mathrm{V}}\right)$, sensörler yardımıyla çıkış akımı ve çıkış gerilimi ölçüldükten sonra hesaplanır. Daha sonra PV panelin iletkenliğindeki değişim $\left(\Delta \mathrm{C}=\Delta \mathrm{I}_{\mathrm{p}} / \Delta \mathrm{V}_{\mathrm{p}}\right)$ hesaplanır [12].

Şekil 9'da görüldüğü gibi PV panelin maksimum güç noktasındaki eğimi sıfırdır. Eğim MGN'nın sağında negatif, solunda ise pozitiftir [16]. Maksimum güç noktasında aşağıdaki denklemin sağlanması gerekir.

$$
\frac{\Delta \mathrm{I}_{\mathrm{pv}}}{\Delta \mathrm{V}_{\mathrm{pv}}}+\frac{\mathrm{I}_{\mathrm{pv}}}{\mathrm{V}_{\mathrm{pv}}}=0
$$

Yukarıdaki denklemin sağlanamaması durumunda aşağıdaki eşitlikler yazılır.

PV panel maksimum güç noktasının sağında çalışıyor ise;

$$
\frac{\Delta \mathrm{I}_{\mathrm{pv}}}{\Delta \mathrm{V}_{\mathrm{pv}}}+\frac{\mathrm{I}_{\mathrm{pv}}}{\mathrm{V}_{\mathrm{pv}}}<0
$$

olmalıdır. PV panel maksimum güç noktasının solunda çalışıyor ise;

$$
\frac{\Delta \mathrm{I}_{\mathrm{pv}}}{\Delta \mathrm{V}_{\mathrm{pv}}}+\frac{\mathrm{I}_{\mathrm{pv}}}{\mathrm{V}_{\mathrm{pv}}}>0
$$

olmalıdır. Şekil 9'da Aİ Yönteminin çalışmasını yukarıdaki eşitliklerle beraber açıklayan güç gerilim eğrisi verilmiştir. Aİ yönteminin algoritması Şekil 10'da verilmiştir. Şekil 10'daki algoritmanın MATLAB simulink ortamında kurulan modeli Şekil 11'da verilmiştir.

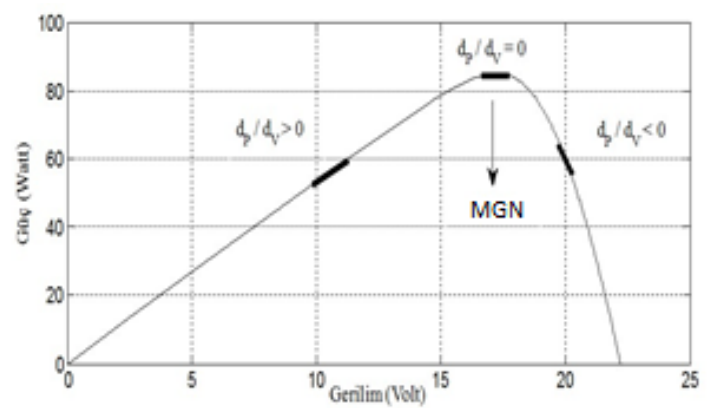

Şekil 9. Aİ güç-gerilim eğrisi

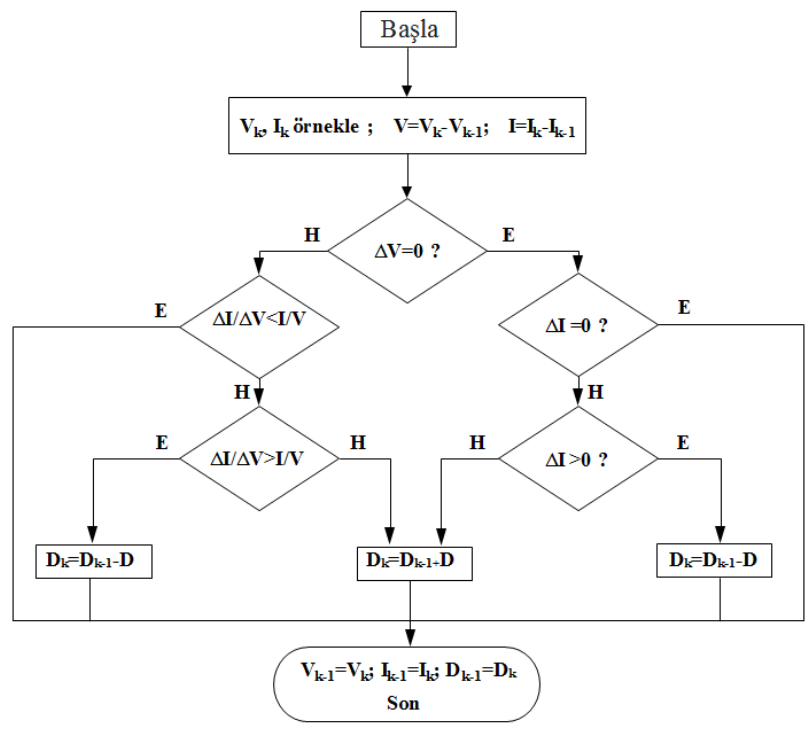

Şekil 10. Aİ yönteminin algoritması [17]

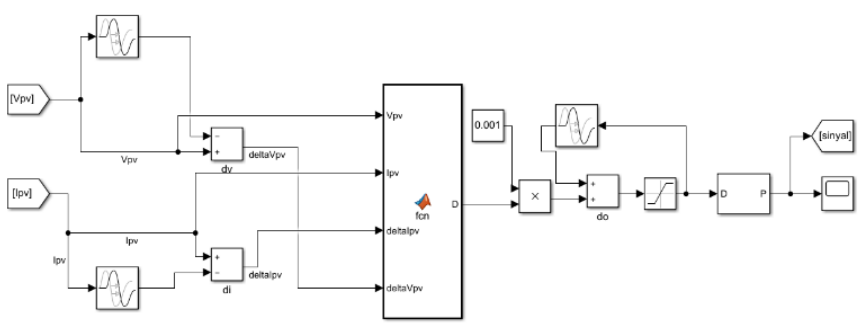

Şekil 11. Aİ algoritmasının MATLAB simulink modeli 


\subsection{Sabit Gerilim Yöntemi}

SG yöntemi maksimum güç noktasındaki gerilim ile açık devre gerilimi arasındaki oranın yaklaşık sabit olduğu esasına dayanmaktadır. $\mathrm{Bu}$ yöntem, tek sensör kullanması ve algoritmanın sadeliği nedeniyle MGNT yöntemleri arasında en basit olanıdır. Güneş paneli geçici olarak açık devre edilerek, açık devre gerilimi ölçülür. Bu yöntemde MGN gerilimi referans alınıp bir PI kontrolcü ile PV sistemi sürekli ve efektif bir şekilde maksimum güç noktasında tutulur [18].

$\mathrm{Bu}$ çalışmada PI kontrolörün değiş̧kenleri olan $\mathrm{Kp}$ ve $\mathrm{Ki}$ değerleri Chien-Hrones-Reswick (CHR) metodu [19] kullanılarak belirlenmiştir. CHR yöntemi Ziegler-Nichols metodunun uyarlanmış halidir. CHR metodu PID parametrelerini ayarlamak için endüstride sıkça kullanılılır. CHR tekniğinde PID parametrelerini belirlemek için zaman sabiti (T), gecikme zamanı (L) ve sabit bir çarpan (k) vardır [20]. Burada parametreleri ayarlamak için $a=k * \mathrm{~L} / \mathrm{T}$ kullanılmaktadır. CHR tekniğinde gecikme zamanı kullanılarak hedef aşımının $\% 0$ ve \%20 olması durumu için gerekli değerler Tablo 3 'te verilmiştir.

Tablo 3. CHR tekniğinde kullanılan $K_{p}, K_{i}$ ve $K_{d}$ değerleri

\begin{tabular}{|c|c|c|c|c|c|c|}
\hline Hedef aşım 1 & \multicolumn{3}{|c|}{$0 \%$} & \multicolumn{3}{c|}{$20 \%$} \\
\hline Kontrolör & $\mathrm{K}_{\mathrm{p}}$ & $\mathrm{K}_{\mathrm{i}}$ & $\mathrm{K}_{\mathrm{d}}$ & $\mathrm{K}_{\mathrm{p}}$ & $\mathrm{K}_{\mathrm{i}}$ & $\mathrm{K}_{\mathrm{d}}$ \\
\hline PID & $0.95 / \mathrm{a}$ & $2.4 \mathrm{~L}$ & $0.42 \mathrm{~L}$ & $1.2 / \mathrm{a}$ & $2 \mathrm{~L}$ & $0.42 \mathrm{~L}$ \\
\hline PI & $0.6 / \mathrm{a}$ & $4 \mathrm{~L}$ & - & $0.7 / \mathrm{a}$ & $2.3 \mathrm{~L}$ & - \\
\hline P & $0.3 / \mathrm{a}$ & - & - & $0.7 / \mathrm{a}$ & - & - \\
\hline
\end{tabular}

Tablo 3 kullanılarak elde edilen $K_{p}$ değeri 1.4 ve $K_{i}$ değeri ise 0.006 olmuştur. Şekil 12'de SG yöntemi için hazırlanan PI kontrolör görünmektedir.

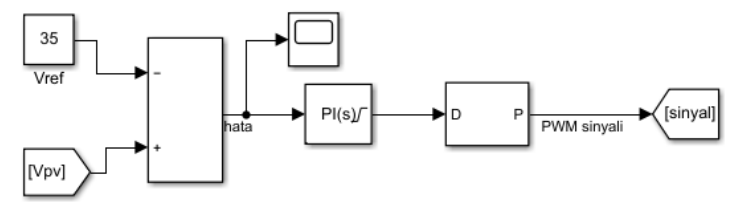

Şekil 12. SG yöntemi PI kontrolörü

Ayrıca, PI kontrolörü panel uçlarındaki açık devre gerilimi ve referans gerilimi arasındaki hata sinyalini düzenleyerek DCDC dönüştürücünün $\lambda$ bağıl iletim süresini belirlemek için kullanılır.

\subsection{Açık Devre Gerilimi Yöntemi}

PV panellerin açık devre gerilimi $V_{a d}$ ile maksimum güç noktası gerilimi $V_{M G N}$ arasında (11) nolu denklemde görüldüğü gibi doğrusal bir ilişki vardır.

$$
\mathrm{V}_{\mathrm{MGN}}=\mathrm{k} . \mathrm{V}_{\mathrm{ad}}
$$

Burada $\mathrm{k}$ birden küçük bir katsayıdır ve genellikle 0.7 ile 0.9 arasında bir değer almaktadır. Bu çalışmada kullanılan ve Tablo 2'de elektriksel özellikleri verilen PV panel için k değeri 0.805 olarak hesaplanmıştır. Şekil 13'de ADG yöntemini incelemek için oluşturulan MATLAB simulink modeli görülmektedir. SG metodunda hesaplanan PI katsayıları ADG yönteminde de kullanılmıştır.
ADG yöntemi SG yöntemine benzemektedir. SG yönteminin gelişmiş versiyonudur. SG yönteminde olduğu gibi bu yöntemde de amaç PV panelin çıkış gerilimini bir PI kontrolör vasıtasıyla referans alınan gerilim değerinde tutmaktır. ADG tekniğinin SG tekniğinden fark1 ise referans gerilim değerinin sürekli olarak güncellenmesidir [21].

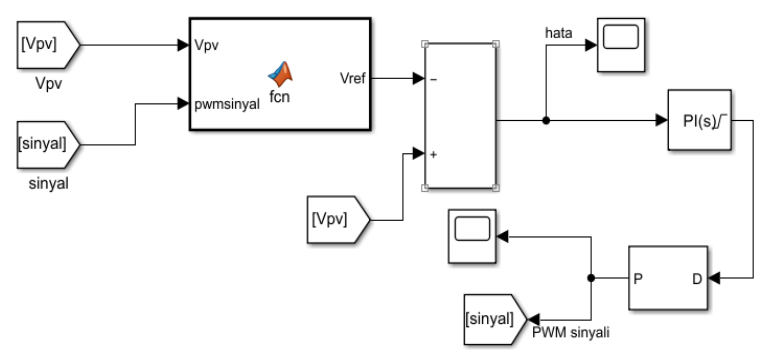

Şekil 13. ADG yöntemi için oluşturulan MATLAB simulink modeli

Şekil 14'te simülasyonda kullanılan panelin farklı 1şıma değerleri için gerilim akım karakteristikleri verilmiştir. Şekil 14 ve Şekil 3'den görüldüğü üzere, 1şınım değeri $500 \mathrm{~W} / \mathrm{m}^{2}$ 'nin altına düş̧üğünde maksimum güç noktasının gerilim değeri değişmektedir. Bu sebeple ADG tekniği, MGN gerilimi değiştiği noktadan itibaren SG tekniğine göre daha iyi sonuç verir.

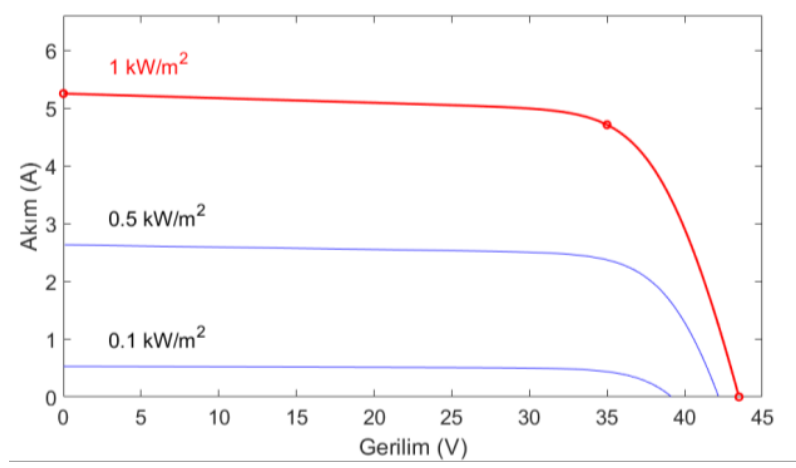

Şekil 14. Farklı 1şıma değerleri için gerilim akım karakteristiği

\section{MGNT Yöntemlerinin Karşılaştırılması}

\subsection{Simülasyon Çalışması}

Şekil $15^{\prime}$ de simülasyon devresinin genel devre şeması görünmektedir. Simülasyon devresinde sırasıyla DG, Aİ, SG ve ADG yöntemleri kullanılarak çalıştırılmıştır. PV panelin girişine gerçek ölçülen sabit sıcaklık ve değişken ışıma değeri girilmiştir. PV panelin çıkışından alınan gerilim ve akım değerleri MGNT bloğuna girer. Burda seçtiğimiz MNGT yönteminin algoritması uygulandıktan sonra çıkışta oluşan kontrol sinyali DC-DC dönüştürücünün anahtarlama elemanına uygulanmıştır. PV panel çıkışına bağlanan düşürücü dönüştürücü PV gerilimini batarya şarj gerilimine düşürerek, bataryayı sabit gerilimde şarj eder. Yıldız Teknik Üniversitesi Davutpaşa Yerleşkesinde 19 Eylül 2019 tarihinde yapılan 762 dakika süren 1şıma ölçümlerinin ortalaması $468 \mathrm{~W} / \mathrm{m}^{2}$ olarak hesaplanmıştır. Şekil 16'da gerçek 1şıma değerlerinin ortalaması ile aynı ortalamaya sahip olan saat 12:51 ile 13:01 saatleri arasındaki veriler alınmıştır. Ayrıca, verilen grafik çok aşamalı olduğundan MGNT tekniklerinin analizi yapılırken gerçeğe daha yakın sonuçlar alınabilecektir. 


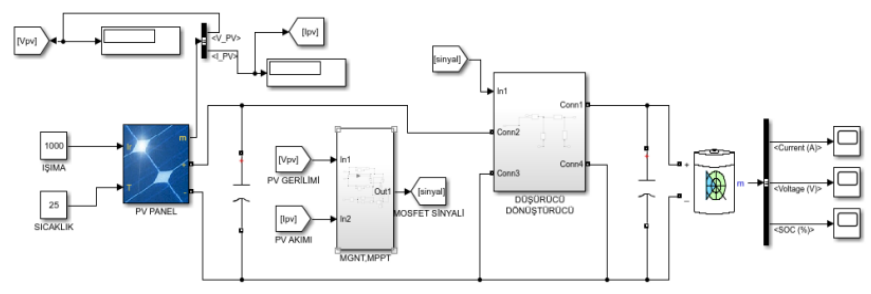

Şekil 15. Simülasyonun devre şeması

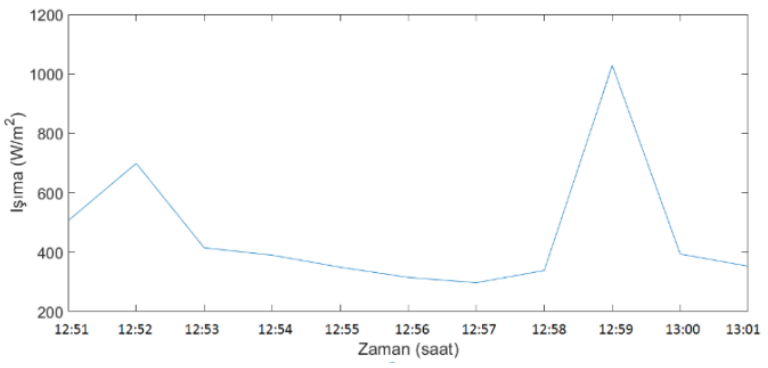

Şekil 16. Simülasyonda kullanılan ışıma

\subsection{Simülasyon Sonuçları}

Simülasyonlar, Şekil $16^{\prime}$ da verilen ışıma verisine göre $25^{\circ} \mathrm{C}$ sabit sıcaklık değerinde, 3.3 sn. çalıştırılarak 1000 örnekleme alınarak yapılmıştır. Ayrıca Şekil 3'den görüleceği üzere ortalama $468 \mathrm{~W} / \mathrm{m}^{2}$ 1şıma değeri için panelden alınabilecek maksimum çıkış gücü yaklaşık olarak 75.83 W'tır.

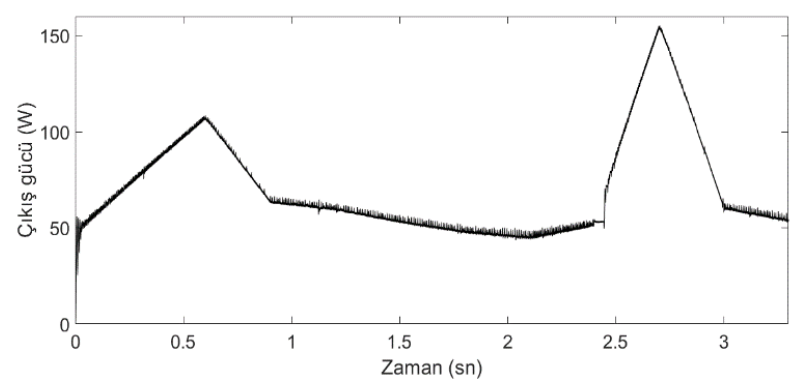

Şekil 17. DG çıkış gücü

Şekil 17'de, DG tekniğine ait çıkış gücünün değişimi verilmiştir. Burada ortalama çıkış gücü $72.49 \mathrm{~W}$ olarak ölçülmüştür. Grafik incelendiğinde ilk olarak göze çarpan çıkış gücündeki küçük dalgalanmalardır. $\mathrm{Bu}$ dalgalanmalar, Şekil 10 'daki algoritmaya dikkat edilirse DG tekniğinde güç değerine bağlı olarak düşürücü DC-DC dönüştürücünün $\lambda$ doluluk oranının lineer olarak azaltılıp arttırılmasından kaynaklanmaktadır.

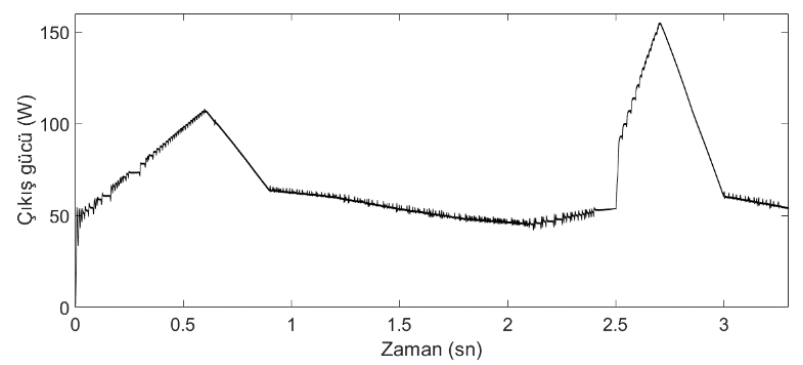

Şekil 18. Aİ çıkış gücü

Şekil 18'de 1şımanın sürekli değişmesine bağlı olarak Aİ yönteme ait çıkış gücünün değişimi verilmiştir. Elde edilen sonuçlara göre yüke aktarılan güç $72.5 \mathrm{~W}$ olarak ölçülmüştür.
Burada aynı DG tekniğginde olduğu gibi küçük salınımlar mevcuttur. Bunun sebebi ise yine DG tekniğinde olduğu gibi $\lambda$ doluluk oranının doğrusal olarak arttırılıp azaltılmasından kaynaklanmaktadır.

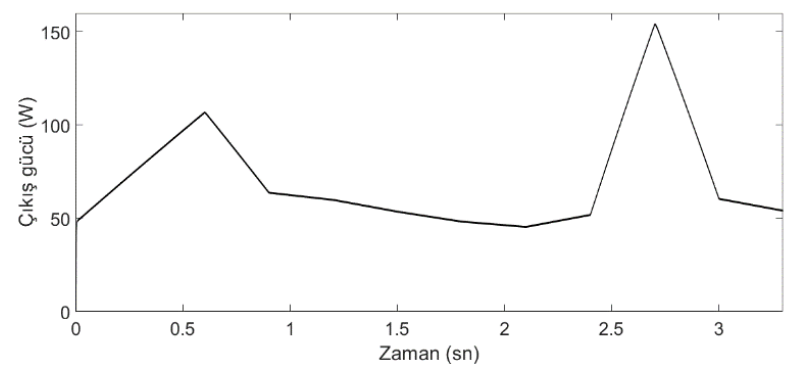

Şekil 19. SG çıkış gücü

Şekil 19'da değiş̧ken 1şıma değeri altında SG tekniğinden yüke aktarılan gücün zaman ile değişimi görülmektedir. Verilen grafikte ortalama çıkış gücü $68.97 \mathrm{~W}$ olarak ölçülmüsştür. Burada çıkış gücünün grafiğgi daha az salınımlı olmasına rağmen ortalama çıkış gücü, DG ve Aİ yöntemlerine kıyasla daha düşük çıkmıştır. Denklem 11'den görüleceği gibi, PI kontrolör sabit bir gerilim noktasını takip etmektedir. Şekil 3' incelendiğinde ışıma değeri değiştiğinde MGN gerilim noktasıda yer değiştirmektedir. $\mathrm{Bu}$ nedenden dolayı $\mathrm{SG}$ tekniğinde çıkışa aktarılan güç düşük çıkmıştır. PI kontrolörü kullanılmasından dolayı bu teknikte elde edilen grafikteki salınımlar diğer iki yönteme göre daha az olmuştur.

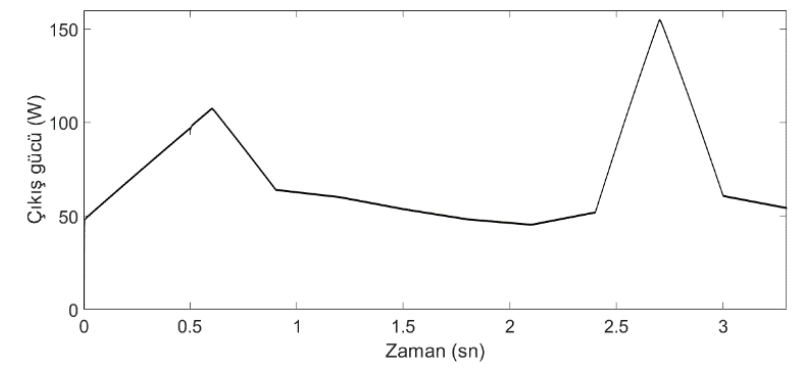

Şekil 20. ADG çıkış gücü

Şekil 20'de yine aynı değişken ışıma değeri için ADG yönteminin zamana bağlı çıkış gücünün değișimi verilmiştir. Burada yüke aktarılan ortalama çıkış gücü $71.09 \mathrm{~W}$ olarak ölçülmüştür. SG tekniğinde olduğu gibi PI kontrolör kullanıldığından çıkış gücü salınımı çok azdır. ADG tekniği belirli aralıklarla denklem 11'e göre yeni MGN'nı aradığından elde edilen çıkış gücü SG gerilim tekniğine göre daha fazladır. Öte yandan DG veya Aİ gibi anlık olarak MGNT yapmadığından yüke aktardığı güç de gradient tabanlı yöntemler olan Aİ ve DG tekniklerinden daha düşüktür.

$\mathrm{Bu}$ dört yöntem kullanılarak önerilen sistemin maksimum güç noktası takibi yapılmıştır. Simülasyonlarda kullanılan Aavid Solar ASMS-165P panelinden $25^{\circ} \mathrm{C}$ sabit sicaklık ve ortalama $468 \mathrm{~W} / \mathrm{m}^{2}$ 1şıma değeri için alınabilecek teorik maksimum çıkış gücü yaklaşık olarak $75.83 \mathrm{~W}$ 'dır. Bu güç değeri, kayıpların ihmal edilmiş olma durumu yani devrenin ideal olma durumunda alınabilecek güç değeridir. Her bir yöntem için ayrı ayrı elde edilen maksimum güç değerleri bu teorik güç değerine oranlandığı takdirde, ilgili yöntemin verim değeri bulunmuş olur. MGNT yöntemlerine ait ortalama çıkış güç değerleri ile hesaplanan verimler Tablo 3’te verilmiştir. 
Tablo 4. MGNT yöntemlerinin karşılaştırılması

\begin{tabular}{l|c|c|c|c|c}
\hline \multirow{2}{*}{ Kriter } & \multirow{2}{*}{$\begin{array}{l}\text { Teorik } \\
\text { Beklenti }\end{array}$} & \multicolumn{4}{|c}{ MGNT yöntemleri } \\
\cline { 3 - 6 } & & DG & Aİ & SG & ADG \\
\hline $\begin{array}{l}\text { Çık1ş gücü } \\
\text { (W) }\end{array}$ & 75.83 & 72.49 & 72.50 & 68.97 & 71.09 \\
\hline Verim (\%) & 100 & 95.59 & 95.6 & 90.95 & 93.74 \\
\hline
\end{tabular}

\section{Sonuç}

Enerji ihtiyacının giderek artmasıyla birlikte çevreci ve yenilenebilir enerji kaynaklarına yöneliş artmaktadır. PV santrallerin küçük güçte kurulumu panel maliyetlerinin azalması ve kullanım kolaylığı nedeniyle yaygınlaşmaktadır. Güneş enerjisinin üretildiği $\mathrm{PV}$ panellerin birçok parametreden etkilenmesinden ötürü düşen verimlerinin kontrol edilerek artırılması için mekanik yöntemlerin yanısıra elektronik yöntemlerin de kullanımı gerekmektedir. $\mathrm{Bu}$ çalışmada, literatürde en çok kullanılan iki gradient tabanlı MGNT yöntemi olan Aİ ve DG yöntemleri ve iki pasif MGNT yöntemi olan SG ve $A D G$ teknikleri verim ve çıkış gücü açısından incelenmiş ve değiş̧ken 1 şınım altında performasları kıyaslanmış̧ır. PV panel olarak $164.85 \mathrm{~W}$ gücünde ve MGN gerilimi $35 \mathrm{~V}$ olan bir panel kullanılmıştır. PV panellerden elde edilen çıkış gerilimi bataryanın şarj edilmesinde kullanmak için 12 V'a düşürülmüştür. Gerilimi ayarlamak için, şarj akımında $1 \mathrm{~A}$, şarj geriliminde $0.4 \mathrm{~V}$ dalgalanmaya müsaade eden anahtarlama frekans1 $20 \mathrm{kHz}$ olan düşürücü DC-DC dönüştürücü tasarlanmıştır. MGNT yöntemlerinin herbiri tasarlanan dönüştürücü sayesinde MATLAB $^{\circledR}$ Simulink programında modellenmiş ve yöntemlerin performansları sabit $25^{\circ} \mathrm{C}$ sıcaklıkta değişken 1şıma değeri için karşılaştııılmıştır. Simülasyonlarda, 19 Eylül 2019 tarihindeki Yıldız Teknik Üniversitesi Davutpaşa yerleşkesinden alınan ve ortalaması 468 $\mathrm{W} / \mathrm{m}^{2}$ olan 762 dakikalık gerçek ışıma değerleri kullanılmıştır. Sonuçlara göre gradient tabanlı takip tekniklerinde kullanılan kontrol yönteminden dolayı çıkış gücündeki dalgalanma pasif yöntemlerinki ile kıyaslandığında daha yüksektir. Gradient tabanlı yöntemlerin maksimum güç noktasına yaklaşma performansları pasif yöntemlere göre daha iyidir. Bunun yanısıra PV panelden çekilen güç bakımından da gradient tabanlı yöntemlerin daha verimli olduğu gözlenmiştir.

\section{Kaynakça}

[1] Z. Çelik, A. S. Yılmaz, and E. Sert, "Mikro Şebeke Bağlantılı Güneş Enerji Üretim Sistemlerinin Kontrolü," KSU. J. Eng. Sci., vol. 18, no. 2, pp. 41-48, 2015.

[2] O. Arikan, B. Kekezoglu, A. Durusu, E. Isen, A. Erduman, and A. Bozkurt, "Comparison of Charge Controllers on PV Panel Performance: An Experimental Study," Int. J. Adv. Electron. Electr. Eng., vol. 3, no. 3, pp. 121-125, 2014.

[3] L. L. Oscar, M. T. Penella, and M. Gasulla, "A new MPPT method for low-power solar energy harvesting," IEEE Trans. Ind. Electron., vol. 57, no. 9, pp. 3129-3138, 2010.

[4] J. J. Nedumgatt, K. B. Jayakrishnan, S. Umashankar, D. Vijayakumar, and D. P. Kothari, "Perturb and observe MPPT algorithm for solar PV systems-modeling and simulation," in 2011 Annual IEEE India Conference, 2011, vol. 19, no. 1, pp. 1-6.

[5] P. K. Jena, A. Mohapatra, Srikanth and P. Choudhary, "Comparative study of solar PV MPPT by Perturbation and Observation and Fuzzy method," 2016 IEEE Uttar Pradesh Section International Conference on Electrical, Computer and Electronics Engineering (UPCON), Varanasi, pp. 515518, 2016.

[6] M. P. Raj and A. M. Joshua, "Modeling and performance analysis of perturb \& observe, incremental conductance and fuzzy logic MPPT controllers," 2017 International Conference on Advances in Electrical Technology for Green Energy (ICAETGT), Coimbatore, pp. 13-18, 2017.

[7] O. Ezinwanne, F. Zhongwen, and L. Zhijun, "Energy Performance and Cost Comparison of MPPT Techniques for Photovoltaics and other Applications," Energy Procedia, vol. 107, no. September 2016, pp. 297-303, 2017.

[8] M. A. G. de Brito, L. Galotto, L. P. Sampaio, G. d. A. e Melo, and C. A. Canesin, "Evaluation of the Main MPPT Techniques for Photovoltaic Applications," IEEE Trans. Ind. Electron., vol. 60, no. 3, pp. 1156-1167, 2013.

[9] A. K. Gupta, Y. K. Chauhan, and T. Maity, "Experimental investigations and comparison of various MPPT techniques for photovoltaic system," Sadhana - Acad. Proc. Eng. Sci., vol. 43 , no. 8, pp. 1-15, 2018.

[10]E. Akboy, "Yüksek Güç Faktörlü Şebeke Bağlı Bir PV Sistemin Modellenmesi ve Farklı Işınımlar Altında Kontrolü,” Eur. J. Sci. Technol., pp. 794-802, Dec. 2019.

[11]B. Subudhi and R. Pradhan, "A Comparative Study on Maximum Power Point Tracking Techniques for Photovoltaic Power Systems," IEEE Trans. Sustain. Energy, vol. 4, no. 1, pp. 89-98, 2013.

[12]P. Sivakumar, A. Abdul Kader, Y. Kaliavaradhan, and M. Arutchelvi, "Analysis and enhancement of PV efficiency with incremental conductance MPPT technique under nonlinear loading conditions," Renew. Energy, vol. 81, pp. 543550, 2015.

[13]N. H. Baharudin, T. M. N. T. Mansur, F. A. Hamid, R. Ali, and M. I. Misrun, "Performance Analysis of DC-DC Buck Converter for Renewable Energy Application," J. Phys. Conf. Ser., vol. 1019, p. 012020, Jun. 2018.

[14]D. S. Karanjkar, S. Chatterji, S. L. Shimi, and A. Kumar, "Real time simulation and analysis of maximum power point tracking (MPPT) techniques for solar photo-voltaic system," 2014 Recent Adv. Eng. Comput. Sci. RAECS 2014, pp. 1-6, 2014.

[15]Y. E. Keskin, M. E. Başoğlu, İ. G. Tekdemir, and B. Çakır, "Comparison of $\mathrm{P} \& \mathrm{O}$ and Incremental Conductance Algorithms for Photovoltaic Systems," in Elektrik Elektronik - Bilgisayar ve Biyomedikal Mühendisliği Sempozyumu, 2014, pp. 91-95.

[16]S. E. Dagteke and S. Unal, "Comparative analysis of maximum power point tracking methods for rapid environmental changes," in 2015 23nd Signal Processing and Communications Applications Conference (SIU), pp. 1337-1340, 2015.

[17]O. Kırcioğlu, M. Ünlü, and S. Çamur, "Değiştir\&gözle ve artımsal iletkenlik algoritmalarının EN 50530 dinamik verim testine göre performanslarının değerlendirilmesi," SAÜ Fen Bilim. Enstitüsü Derg., vol. 22, no. 1, pp. 85-93, 2018.

[18]M. Lasheen, A. K. Abdel Rahman, M. Abdel-Salam, and S. Ookawara, "Adaptive reference voltage-based MPPT 
technique for PV applications," IET Renew. Power Gener., vol. 11, no. 5, pp. 715-722, 2017.

[19]S. Sheel and O. Gupta, "New Techniques of PID Controller Tuning of a DC Motor - Development of a Toolbox," MIT Int. J. Electr. Instrum. Eng., vol. 2, no. 2, pp. 65-69, 2012.

[20]A. Basu, S. Mohanty, and R. Sharma, "Tuning of FOPID Controller for Meliorating the Performance of the Heating Furnace Using Conventional Tuning and Optimization Technique,” Int. J. Electron. Eng. Res., vol. 9, no. 1, pp. 975-6450, 2017.

[21]S. M. Ferdous, M. A. Mohammad, F. Nasrullah, A. M. Saleque, and A. Z. M. S. Muttalib, "Design and simulation of an open voltage algorithm based maximum power point tracker for battery charging PV system," 2012 7th Int. Conf. Electr. Comput. Eng. ICECE 2012, no. 2, pp. 908-911, 2012. 